\title{
Bimetallic Ruthenium Vinyl Complexes Bridged by Electronic Substituent Phenylenes: Spectroelectrochemical and Computational Studies
}

\author{
Jing Zhang ${ }^{1}$, Chao-Fang Sun ${ }^{1}$, Xiang-Hua $\mathrm{Wu}^{2}$, Ming-Xing Zhang ${ }^{1}$, Jun Yin ${ }^{1}$, Guang-Ao Yu ${ }^{1}$, \\ Sheng Hua Liu ${ }^{1, *}$ \\ ${ }^{1}$ Key Laboratory of Pesticide and Chemical Biology, Ministry of Education, College of Chemistry, \\ Central China Normal University, Wuhan 430079, P.R. China \\ ${ }^{2}$ College of Chemistry and Chemical Engineering, Yunnan Normal University, Kunming 650500, \\ P.R. China \\ *E-mail: chshliu@mail.ccnu.edu.cn
}

doi: $10.20964 / 2016.09 .34$

Received: 29 January 2016 / Accepted: 4 July 2016 / Published: 7 August 2016

A combination of in-situ IR and UV/vis/NIR spectroelectrochemistry and DFT/TDDFT calculations have been employed to explore the spectroscopic and electronic properties of a series of dinuclear ruthenium vinyl complexes $\mathbf{1 a - 1 d}\left[\mathrm{RuCl}(\mathrm{CO})(\mathrm{PMe})_{3}\right]_{2}(\mu-\mathrm{CH}=\mathrm{CH}-\mathrm{Ar}-\mathrm{CH}=\mathrm{CH})\left(\mathrm{Ar}=\mathrm{C}_{6} \mathrm{H}_{2}\left(\mathrm{CH}_{3}\right)_{2}-2,5\right.$ (1a), $\mathrm{C}_{6} \mathrm{H}_{2}\left(\mathrm{OCH}_{3}\right)_{2}-2,5$ (1b), $\mathrm{C}_{6} \mathrm{H}_{2} \mathrm{~F}_{2}-2,5$ (1c) and $\mathrm{C}_{6} \mathrm{H}_{2}\left(\mathrm{CF}_{3}\right)_{2}-2,5$ (1d)). The spectroelectrochemical results combined with theoretical calculations reveal that there are no real electronic couplings between two ruthenium centers for 1a-1d despite high half-wave potential splittings observed. The complexes 1a-1d are characterized by localized oxidations of the bridging ligands and electronreleasing substituents render these localized oxidation processes more facile. In addition, the observed strong near-IR absorptions of $[\mathbf{1 a}]^{+}$and $[\mathbf{1 b}]^{+}$are mainly attributed to the metal-to-ligand chargetransfer (MLCT) transitions.

Keywords: Ruthenium Vinyl Complexes, Electronic Substituent, DFT Calculations, Phenylene Bridge.

\section{FULL TEXT}

(C) 2016 The Authors. Published by ESG (www.electrochemsci.org). This article is an open access article distributed under the terms and conditions of the Creative Commons Attribution license (http://creativecommons.org/licenses/by/4.0/). 